\title{
REABILITAÇÃO PSICOSSOCIAL E FAMÍLIA: CONSIDERAÇÕES SOBRE A REESTRUTURAÇÃO DA ASSISTÊNCIA PSIQUIÁTRICA NO BRASIL*
}

\author{
PSYCHOSOCIAL REHABILITATION AND FAMILY: CONSIDERATIONS ABOUT THE RE-STRUCTURATION OF \\ THE PSYCHIATRIC ASSISTANCE IN BRAZIL
}

REHABILITACIÓN PSICOSSOCIAL E FAMILIA: CONSIDERACIONES SOBRE LA REESTRUCTURACIÓN DE LA ASISTENCIA PSIQUIATRICA EN BRASIL

\author{
Valéria Cristina Christello Coimbra ${ }^{1}$ \\ Jacileide Guimarães ${ }^{2}$ \\ Mariluci Camargo Ferreira da Silva ${ }^{3}$ \\ Luciane Prado Kantorski ${ }^{4}$ \\ Maria Cecília Morais Scatena ${ }^{5}$
}

\begin{abstract}
RESUMO: Trata-se de um ensaio sobre a reestruturação da assistência psiquiátrica no Brasil, com enfoque sobre o campo de interlocução possibilitado entre a reabilitação psicossocial e família. A reestruturação da assistência psiquiátrica no Brasil foi oficializada a partir de 1990, na esteira da Declaração de Caracas, da qual o Brasil é signatário. Este processo prioriza a substituição progressiva dos hospitais psiquiátricos tradicionais por serviços substitutivos, cuja principal característica é a abertura das relações e práticas desenvolvidas. Outras medidas de incentivo à reestruturação foram aprovadas pelo Ministério da Saúde na década de 1990 e endossadas pelas experiências, que se multiplicam no Brasil, de serviços substitutivos ao modelo hospitalocêntrico. A reabilitação psicossocial inscreve-se como traço antigo, porém redefinindo-se nesse processo e, aqui, visamos abordá-la no que tange a sua interface com a família da pessoa com sofrimento psíquico.
\end{abstract}

PALAVRAS CHAVES: Reabilitação; Psiquiatria Comunitária; Família.

ABSTRACT: We describe here a study about the re-structuration of the psychiatric assistance in Brazil. It is focused the interlocution field that is possible between the psychosocial rehabilitation and the family. The restructuration of the psychiatric assistance in Brazil was oficialized in 1990, in the wake of the Caracas Declaration, wich Brazil is a signatory. In this process, the priority is the progressive substitution of the tradicional psychiatric hospitals for substitutive services, with the main characteristic is opening the relationships and practices that are developed. There are others actions that have encouraged the re-structuration and were approved by the Brazilian Health Ministery in the 1990. These actions were endorsed by the experiences of the substitutive services to the hospitalocentric model. The psychosocial rehabilitation is an old concept that is, however, re-defining in this process. In this article, the psychosocial rehabilitation is approached regarding its interface with the family of the mental disturbed person.

KEY WORDS: Rehabilitation; Community Psychiatry; Family

RESUMEN: Trata-se de uno ensayo sobre la reestructuración de la asistencia psiquiátrica no Brasil, con enfoque sobre lo campo de la interlocución posibilitado entre la rehabilitación psicossocial y familia. La reestructuración de la asistencia psiquiátrica no Brasil, fue propugnada oficialmente a partir de 1990, en la estera de la Declaración de Caracas, de la cual lo Brasil é signatario. Este proceso prioriza la substitución progresiva de los hospitales psiquiátricos traicionáis por unidades substitutivas, cuja principal característica é la abertura de las relaciones y prácticas desenvolvías. Otras medidas de incentivo la reestructuración, furam aprovadas pelo Ministério de la Salud na década de 1990 y endossadas pelas experiências, que sé multiplicam no Brasil, de serviços substitutivos ao modelo hospitalocêntrico. La rehabilitación psicossocial inscribe-se como traço, antigo, mas redefinindo-se, nesse processo e, aqui, visamos abordá-la, no que tange la suja interfase com la familia de la persona com sufrimiento psíquico.

PALAVRAS CLAVES: Rehabilitación; Psiquiatría Comunitaria; Familia.

\section{INTRODUÇÃO}

Nas últimas décadas a assistência psiquiátrica vem se modificando, o modelo tradicional vem sendo substituído por serviços substitutivos que visam a o atendimento na comunidade. Nestes espaços, o ato de cuidar exige dos profissionais uma postura técnopolítica constante, que mobilize e envolva a comunidade. Para isso, deveria haver maior responsabilização das pessoas e famílias, com a finalidade de construir com elas melhor qualidade de vida (CABRAL, 2001).

Neste novo modelo, o portador de sofrimento psíquico é atendido na própria comunidade visando a sua reabilitação psicossocial e sua família deve participar de seu tratamento. Neste artigo pretendemos abordar a participação da família na reabilitação psicossocial. 
COIMBRA, Valéria Cristina Chistello; GUIMARÃES, Jacileide; SILVA, Mariluci Camargo Ferreira da; KANTORSKI, Luciane; SCATENA, 100 Maria Cecília Morais - Reabilitação psicossocial e família: considerações sobre a reestruturação da assistência psiquiátrica no Brasil. Revista Eletrônica de Enfermagem, v. 07, n. 01, p. 99 - 104, 2005. Disponível em www.fen.ufg.br/revista.htm

\section{Família e Psiquiatria/Saúde Mental}

Até o século XIV, portanto na pré-modernidade, a família era caracterizada através da linhagem, sendo a primogenitura o seu meio de reprodução privilegiada. Segundo ARIÉS (1978) a família era uma realidade moral e social, mais do que sentimental. Tanto que nesse período, em geral, as crianças eram entregues a mestres de outras famílias estranhas para que melhor se efetivasse a aprendizagem das boas maneiras.

$\mathrm{Na}$ modernidade, período compreendido do século XIV à primeira metade do século $X X$, nasce então, o sentimento de família, tal qual conhecemos até hoje.

Da década de 50 aos dias atuais, vivemos sobre a definição polêmica de pós-modernidade, que não encontra unanimidade entre os estudiosos. Esse período caracterizado por transformações nas formas de organização da vida e do trabalho, recebe a denominação de neoliberalismo no âmbito político; globalização no âmbito econômico e, pós-modernidade na esfera cultural, mais precisamente, nas artes. A família nesse contexto também sofreu transformações marcadas pela pluralidade e diversidade com relação aos padrões até então vigentes, em geral, solidamente, de ordem sentimental moralizada.

No dizer de PERROT (1993) família ambígua, essa da modernidade! Ninho e nó, refúgio caloroso, centro de intercâmbio afetivo e sexual, barreira contra a agressão exterior, mas também secreta, fechada, exclusiva, normativa, palco de incessantes conflitos que tecem uma interminável intriga.

Com isso, no seio da família moderna: alguns aspectos são redimensionados como a autoridade até então valorizada passa a ser criticada e até mesmo abandonada; a afetividade que era regida por normas rígidas e contidas busca expressão livre; a cristalização das exigências com relação às obrigações morais é progressivamente relegada, o que abre espaço para as idiossincrasias, onde a "ausência do proibido" leva ao estabelecimento da comunicação uníssona e autoritária dá lugar ao desejo de "expressar tudo".

Concordamos com PERROT (1993), quando diz que não é a família em si que a contemporaneidade recusa, mas o modelo excessivamente rígido e normativo que assumiu no século XIX, nesse sentido, a rejeição é do nó, não o ninho. A casa é, cada vez mais, o centro da existência. O lar oferece, num mundo duro, um abrigo, uma proteção, um pouco de calor humano, o que se deseja é conciliar as vantagens da solidariedade familiar e as da liberdade individual. Ainda PERROT (1993) sintetiza razoavelmente os anseios da família neste fim/começo de século/milênio: o que se gostaria de conservar da família, no terceiro milênio, são seus aspectos positivos: a solidariedade, a fraternidade, a ajuda mútua, os laços de afeto e o amor. Belo sonho!

Grosso modo, a idéia de um amanhã a ser construído, tão bem representado pela institucionalização da vida veiculada na modernidade, perde espaço para o presenteísmo exigido pela pós- modernidade, a desinstitucionalização aqui parece o emblema, por excelência, dessa transformação.

Ou conforme COELHO (1999) a noção do social racionalizado, próprio do século XIX, enfraquece e tende a ser substituído por um estar-junto que aponta para um ideal comunitário a ser vivido sob o guardachuva (não exclusivo) do localismo.

No que se refere ao âmbito dos saberes e práticas sobre a pessoa com sofrimento psíquico, psiquiatria/saúde mental versus família são velhos interlocutores que, em geral, até o final da década de 1970 no Brasil, ora se confrontaram, ora se aliaram em nome de uma pseudoterapia: 0 isolamento do chamado doente mental. Segundo BIRMAN (1978), o confronto instaura-se entre as duas instituições (psiquiatria e família), na passagem do paciente que ameaça a família para a família que propicia a alienação mental e, a superposição dos discursos beneficia a psiquiatria, então ratificadora da disciplinarização da sociedade, que introduziu no discurso familiar, o discurso psiquiátrico visa a dupla normatização de pais e filhos no âmbito da família nuclear que então representa a célula mater da sociedade.

Dessa relação pouco legítima, a consideração do paciente psiquiátrico como sujeito, redundou os índices elevados de internados cronificados nos manicômios brasileiros. Numa palavra e sem receio de exagerarmos, haja vista, a realidade histórica da assistência psiquiátrica no Brasil, psiquiatria e família, até muito recentemente relegaram a pessoa com sofrimento psíquico ao abandono pessoal e social. Dada à presença desse abandono até bem pouco tempo, dispensamos o risco de anacronismo nesse traço da assistência psiquiátrica.

No Brasil, o reflexo do questionamento sobre a instituição psiquiátrica tradicional que ocorreu no mundo após a segunda guerra mundial, chega no final da década de 1970, com o Movimento dos Trabalhadores em Saúde Mental. Esse movimento, associado/possibilitado pela abertura democrática do contexto político do país, abriu precedentes para o questionamento do saber/prática psiquiátrica nos moldes das inquietações advindas das experiências italianas lideradas por Franco Basaglia, que aqui esteve em 1979, proferindo conferências e intercâmbio da prática em Gorizia e em Triestre.

$\mathrm{Na}$ década de 90, trabalhadores de saúde mental mobilizaram familiares e usuários de serviços psiquiátricos no Brasil e criaram o Movimento de Luta Antimanicomial. Nesse contexto da polêmica pósmodernidade, a desinstitucionalização em psiquiatria/saúde mental propunha um novo projeto terapêutico que engloba a reabilitação psicossocial da pessoa com sofrimento psíquico, e para tanto, o envolvimento da família é prerrogativa (KANTORSKI, PITIA e MIRON, 2002). Vale destacar que também essa denominação de Reabilitação Psicossocial encontra controvérsias, devido o seu ranço ortopédico, ou seja, a sua carga de determinismo acabado em si, de recomposição de estados de exceção, quando o que se pretende, segundo o questionamento do saber/prática psiquiátrica, é a compreensão com 
COIMBRA, Valéria Cristina Chistello; GUIMARÃES, Jacileide; SILVA, Mariluci Camargo Ferreira da; KANTORSKI, Luciane; SCATENA, 101 Maria Cecília Morais - Reabilitação psicossocial e família: considerações sobre a reestruturação da assistência psiquiátrica no Brasil. Revista Eletrônica de Enfermagem, v. 07, n. 01, p. 99 - 104, 2005. Disponível em www.fen.ufg.br/revista.htm

intervenção sobre o favorecimento das possibilidades e a redução dos limites do diferente.

Portanto, nesses tempos de desinstitucionalização da vida, queiram uns como pósmodernidade ou não, mas certamente um tempo de questionamentos contundentes sobre a instuticionalização da modernidade, os saberes e práticas sobre a pessoa com sofrimento psíquico, buscam e, algumas experiências conseguem, a veiculação, intercâmbio e aliança em torno de uma coparticipação e co-responsabilidade entre trabalhadores, familiares e usuários de serviços de saúde mental no Brasil.

Claro que novas formas de relacionamento geram suas próprias formas de riscos imanentes, nem sempre tão novos. No que concerne a reestruturação da assistência psiquiátrica, não é demais ressaltar a preocupação de Basaglia quando nos adverte para o risco do reformismo psiquiátrico, ou seja, da adaptação de estruturas físicas e regulamentos quando na prática mantém-se a mentalidade manicomial. E aqui fazemos uma ponte com a assistência em saúde em geral, no tocante a atualidade da atenção básica na profusão de discursos sobre o Programa Saúde da Família. Conforme o Ministério da Saúde no documento denominado Por uma Política de Saúde Mental, as diretrizes para a reforma da atenção na Saúde Mental no país se coadunam com a perspectiva do PACS/PSF na promoção à saúde e na reconfiguração do modelo de atenção (BRASIL, 1999). Trata-se de um programa e como tal, instituído de cima para baixo, mas que, em que pese o seu caráter verticalizado e o entusiasmo das políticas governamentais, pode ser subvertido em prol de algo mais do que "uma cesta básica" da saúde, "medicina de pobres". E neste sentido a aliança com a saúde mental desinstitucionalizadora pode contribuir para a horizontalização e frutos novos de assistência integral à comunidade.

\section{Reabilitação Psicossocial e Família}

A Reabilitação Psicossocial pode ser entendida como o processo pelo qual se facilita ao individuo com limitações, a restauração, no melhor nível possível de autonomia de suas funções na comunidade (PITTA, 1996). Já para BERTOLOTE (1996) seria o processo de remoção de barreiras, as quais impedem a plena integração de um individuo na comunidade e o pleno exercício de seus direitos de sua cidadania. Compreendemos que essas barreiras, como o estigma que a doença mental possui, e que permeou a sociedade e família por séculos, ou ainda permeia.

A reabilitação psicossocial não consiste em tornar os fracos em fortes, ao contrário, consiste em mudar as regras do jogo para que os fortes possam se adaptar aos fracos e coexistir no mesmo cenário, a fim de permitir que a pessoa que possua uma desabilidade, freqüente o mesmo cenário onde os fortes estão (SARACENO, 1996). Este autor ainda cita que a reabilitação implica numa mudança total de política dos serviços de saúde mental, e que deve agora englobar os profissionais, usuários, e finalmente a comunidade inteira, sendo assim é um processo que envolve a todos e o "profissional" e o "paciente".

Entendemos que a reabilitação psicossocial visa a não exclusão do portador de sofrimento psíquico, para tanto temos que entendê-lo como um indivíduo único, com vivências próprias, e sua abordagem terapêutica deve ser individualizado. Neste contexto, a família se torna um dos pontos importantes na reabilitação psicossocial, entretanto as famílias e a sociedade pode ser a primeira forma de exclusão, mas para que isto não venha a ocorrer, os trabalhadores da saúde precisam trabalhar com estas famílias e com a comunidade mostrando que os "loucos" não são um ameaço ao bom andamento social (HIRDES, 2000). Nesse sentido, a reabilitação consiste dar aos portadores de sofrimento psíquico o direito de ter resgatado sua cidadania que por muitos anos foi roubada e para isso o envolvimento dos profissionais da saúde se torna essencial.

SARACENO (1999) coloca que a reabilitação psicossocial está centrada em três vértices da vida a casa, trabalho e lazer. A família pode ser um quarto vértice para aqueles usuários que ainda tem algum vínculo familiar, este poderá morar na residência da família, com isso alguns dos objetivos da reabilitação serão contemplados que é o apoio para as famílias dos usuários e apoio social (moradia, emprego, rede social, apoio social e lazer) e suas estratégia deverão ser baseadas na comunidade contando com 0 envolvimento dos indivíduos, familiares e comunidade.

SARACENO (1998) ainda considera que as abordagens reabilitativas devem ser realizadas na rede social familiar por esta encontrar-se mais concreta e definida para a equipe terapêutica, para o paciente e para própria família.

Esta rede social é muito importante na vida do usuário, porque é a partir dela que este vai conseguir se inserir na comunidade. Para SCATENA (2000) o lazer é uma forma de fazer com que o doente mental se aproprie de outros espaços da cidade como praças, museus, cinema, fazendo com que este entre em contato com a comunidade. Essa autora ainda relata que, freqüentemente, nos serviços abertos de saúde mental os usuários reclamam que no fim de semana não possuem possibilidade de sair de casa. Sendo assim, o lazer deveria ser oferecido para os familiares para que com isso possa inserir a família no serviço, promovendo a interação usuário/ família a partir de lazer.

A reabilitação não vê mais a família como vitima ou cúmplice da psiquiatria e sim como protagonista do processo de tratamento. Assim a família é despojada da culpabilização e atua como co-participes na reabilitação (HIRDES, 2000). A família tem um papel importantíssimo, principalmente, no que se refere a propiciar ao usuário melhores condições de vida. Ainda citando HIRDES (2000) o mais importante neste conceito seja a demonstração de que os membros da família podem efetivamente resolver problemas intervir nas crises e promover a recuperação.

Esta mesma autora coloca que muitos estereótipos são abandonados no momento em que as famílias não são culpabilizadas pela doença do usuário 
são tratadas como coajuvantes no tratamento e na reabilitação. Um dos grandes ganhos na inclusão sistemática da família no tratamento e diz respeito à retirada destes estereótipos, por exemplo, por ela ser responsável pela doença do paciente.

Esse processo de reabilitação deve pensar nas condições adversas enfrentadas pelos pacientes antes, durante e após a internação (SARACENO, 1996a). Neste contexto, é importante salientar o conceito de resiliência das famílias que pode ser entendido como a capacidade de construir mudanças e crescer em resposta a uma serie de desordens psiquiátricas de um dos membros da família. Apesar dos encargos da família em face à doença mental, os membros da família podem efetivamente resolver seus problemas, intervir nas crises, promover recuperação de seus familiares com doença mental. Devemos trabalhar com a concepção de resiliência e de sua promoção, o que favorece a mudança de modelo de interpretação dos problemas e de caminhos de resolução (HIRDES, 2000).

VALENTINI \& VICENTE (1996) destacam a importância de conhecermos 0 conceito de desesperança para poder entender o que seria resiliência, esta é quando as pessoas acreditam que elas são importantes para controlar o que acontece com elas tornam-se passivas e restritas em suas habilidades de enfrentamento. Por outro lado, quando os indivíduos acreditam que os eventos e resultados são controláveis, o aprendizado da desesperança é evitado, ao invés disso, tentativas ativas para vencer situações adversas são realizadas, neste caso promovendo a resiliência.

$\mathrm{Na}$ reabilitação os usuários e seus familiares estão deixando de ser apenas objeto de intervenção para assumir o papel de agente transformador da realidade, opinando e participando ativamente das discussões sobre as políticas da saúde mental (MELMAN, 2001). Assim, os serviços teriam que chamar a família para atuar junto e também atuar dentro do seio familiar. Esse envolvimento da família no tratamento dos usuários diminui as recaídas e no número de internações psiquiátricas nos pacientes com transtorno mental severo.

É importante o trabalho com as famílias dos usuários para que esta não exclua os usuários do convívio familiar, já que estas muitas vezes também são marginalizadas pela sociedade, isto leva a uma reação em cadeia, ou seja, ela exclui para não ser excluída e acaba se tornando estigmatizada pelos profissionais de saúde mental. O estudo de NASI, STUMM e HILDEBRANDT (2004) relata o quanto essa experiência pode ser difícil para a família e a importância de incluí-la no plano de cuidados desse processo de atender as pessoas com sofrimento psíquico..

A reabilitação também age diretamente na família, pois ao reabilitar os usuários estes terão condições de realizar algumas atividades, deixando de ser um "improdutivo" ao olhar da família. MELMAN (2001) cita ainda que os paciente psiquiátricos encontram obstáculos para produzir economicamente o que deixaria este em condições de dependência da família e, freqüentemente, algum familiar precisa ficar cuidando da pessoa adoecida e que também o impossibilitara de trabalhar. Em contra ponto a esta situação sabe-se também que muitas famílias vivem da pensão destes familiares adoecidos, tornando este necessário na renda familiar, apesar de ser visto como um incapaz.

Ao envolver a família e ao dar suporte a esta para enfrentar as dificuldades no relacionamento com a loucura, a sobrecarga, a culpa, o isolamento social, a carência de informações, problemas de vinculo com os profissionais de saúde, situações de crise, emergência, conflitos familiares (MELMAN, 2001), diminuiria a carga emocional da família e do próprio usuário aumentando o nível de interação e empatia da família com seu familiar doente.

KANTORSKI et al (2000) ao descrever o serviço de atenção a saúde, ressalta que o serviço tem como característica o acolhimento, a escuta, a responsabilização pela trajetória do individuo nos serviços, o plano terapêutico construído considerando a individualidade do sujeito, a inserção da família e da comunidade. Esta autora ainda cita que o envolvimento dos serviços e usuários com festas de dias comemorativos mostram a importância da rede social no tratamento dos usuários com transtornos e que isso reconstrói a visão familiar e comunitária, se tornando um momento de maior de aproximação da rede social com a "loucura".

Assim, a reabilitação visa a permanência do usuário próximo a família e a rede social, ou seja, o resgate a cidadania $A$ participação efetiva da família conduz ao estabelecimento de estratégias de intervenção mais abrangentes consistentes onde podem ser trabalhadas as dificuldades e necessidades de ambas, familiares e usuários (HIRDES, 2000).

A reabilitação psicossocial é uma prática a espera da teoria, mas esta situação deve ser transitória, pois uma prática não pode existir eternamente sem teoria, ou corremos o risco de retomar antigos modelos de referência (retomar antigas teorias) que geram uma prática tão insatisfatória, ou seguir uma ideologia de capacitar os descapacitados, que a sociedade condenou a marginalidade (SARACENO, 1996).

Reabilitação Psicossocial: reflexões acerca das intervenções de enfermagem junto a familiares.

Atualmente, com o advento da Reforma Psiquiátrica, a prática de enfermagem psiquiátrica é inserida em diversos serviços de atenção ao indivíduo em sofrimento psíquico (Centros/Núcleos de atenção psicossocial, hospital- dia, lares protegidos, etc). e ainda encontra algumas parcerias da saúde mental com a saúde da família, através do Programa de Saúde da Família.

Ao refletirmos sobre a enfermagem na Reabilitação Psicossocial no Brasil, não podemos falar do indivíduo em sofrimento psíquico sem considerar a sua família, ou seja, não se consegue cuidar do portador de transtorno mental com eficácia sem cuidarmos da sua família. Além disso, de acordo com 
COIMBRA, Valéria Cristina Chistello; GUIMARÃES, Jacileide; SILVA, Mariluci Camargo Ferreira da; KANTORSKI, Luciane; SCATENA, 103 Maria Cecília Morais - Reabilitação psicossocial e família: considerações sobre a reestruturação da assistência psiquiátrica no Brasil. Revista Eletrônica de Enfermagem, v. 07, n. 01, p. 99 - 104, 2005. Disponível em www.fen.ufg.br/revista.htm

os princípios do momento atual da Psiquiatria, a família deve ser uma aliada, uma parceira no cuidar.

Nesse sentido, SCATENA (2000) ressalta que a família, direta ou indiretamente, afeta e é afetada por todas as intervenções da Enfermagem Psiquiátrica. Sendo assim, o processo de reabilitação envolve a todos: indivíduo, família, comunidade e profissionais.

A família é apontada como o maior recurso na reabilitação do indivíduo em sofrimento psíquico, por isso deve ser estabelecido uma parceria entre indivíduo, família e profissional.

Com o surgimento e a implantação de serviços de saúde mental extra-hospitalar, não basta esses serviços serem abertos e se localizarem na comunidade, o importante é que estes não reproduzam o saber e as práticas manicominais.

No Brasil, são descritas experiências isoladas de enfermeiros que participam desses novos serviços de atenção ao indivíduo em sofrimento psíquico e a sua família.

KANTORSKI et al (2000) relatam o cotidiano de um Serviço de Atenção Diária em Saúde Mental. Caracterizando o trabalho por categorias, que são: o acolhimento, a escuta e o diálogo. O acolhimento se dá pelo assistir individual, através de consulta médica, psicológica, de assistência social e de enfermagem, e coletivo através de oficinas terapêuticas, consideradas as oficinas de criação coletiva (atividades de trabalhos manuais, esportivas, de culinária, higiene e cuidados pessoais), os encontros festivos (datas comemorativas) e a visita domiciliária. Esses espaços são abertos aos usuários e seus familiares possibilitando a aproximação dos membros da equipe e dessa maneira fazer um acompanhamento individual e coletivo.

A escuta e o diálogo é realizado através desses mesmos espaços anteriormente comentados, das assembléias semanais com a equipe, usuários e familiares, grupos de conversação e expressão, grupos de familiares e de medicação, e nas reuniões de equipe. A realização desses grupos favorece 0 encontro de usuários e familiares, a elucidação de dúvidas sobre problemas relacionados à administração e efeitos colaterais dos medicamentos, e a conversação e a expressão dos participantes. Por meio dessas ações os serviços podem ser estruturados com base nos princípios da Reforma Psiquiátrica tornando-se terapêuticos KANTORSKI et al. (2000).

Nesse sentido HIRDES (2000) indaga que abordagens a familiares consistentes com a reabilitação psiquiátrica, provem as famílias com informações e aumento na capacidade para a negociação de situações problemáticas. Outros autores citados pela mesma autora comentam a utilização de um dia único em que realizam uma oficina com os familiares abordando conhecimentos sobre doença mental, trabalhando com a premissa que o conhecimento tem força nele próprio.

HIRDES (2000) coloca a importância da democratização do conhecimento para toda a equipe, ou seja, todos os seus membros precisam ter acesso a esse conhecimento para um desenvolvimento uniforme do serviço. Caso contrário deve imperar a dicotomia entre a prática e a teoria e a falta de integração entre a equipe. Sendo que a desintegração da equipe constitui-se numa variável desfavorável ao desenvolvimento da enfermidade, comprometendo a eficácia das intervenções.

As atitudes de respeito e afeto com o usuário e seus familiares deverão constituir um bom serviço de saúde mental. Esses aspectos são considerados relevantes para a reabilitação o acolhimento, o escutar o outro e tratamento como ser humano. As oficinas não são o que tornam o serviço melhor, pois podem se constituir como locais de entretenimento e não de reabilitação, ou seja, o diferencial do serviço está na abordagem de um cuidar humanizado.

\section{CONSIDERAÇÕES FINAIS}

Concordamos com BASSIT (1992) quando diz que não podemos fazer um raciocínio único e global do tipo: a família cria seu doente ou o doente cria distúrbios na família. A essa idéia acrescentamos que não devemos cristalizar as políticas públicas em sua predominante inoperância histórica sob o olhar conivente da omissão e, também, não é producente encerrarmos a pós-modernidade em um fenômeno inexoravelmente bom ou ruim.

Esse pensamento nos coloca diante de uma tríade - sofrimento psíquico, políticas públicas e pósmodernidade - que é permeada por possibilidades e limites passíveis de transformações positivas através da ação humana, como qualquer processo.

Afinal, essa é a metáfora desse nosso tempo, no dizer de IANNI (1998), simultaneamente globalizado e diverso; agrário, industrial e pós-industrial; integrado e fragmentado. A cidade global que transita entre ostentações e simulacros, também nos acena com a superação do anacronismo da razão iluminista, para uma ética da solidariedade frente às novas formas de coisificação e exclusão da vida.

Assim, a reabilitação é um processo que envolve varias instâncias como o individuo, a família e a comunidade em todos estes esforços desafios e conflitos a serem vencidos. Acrescentamos ainda, que as ações em conjunto dos profissionais de saúde, familiares, sociedade e usuários darão novos frutos para a psiquiatria, pois a reabilitação já é um avanço no que se refere ao tratamento dos portadores de sofrimento psíquico que foi o seu reconhecimento como cidadão, pois atrás de um louco ameaçador, há um ser humano, ou melhor, com já dito um cidadão.

O momento de construção de "uma nova" assistência de Enfermagem Psiquiátrica aponta para a necessidade do conhecimento e utilização de um referencial teórico da Reforma Psiquiátrica. Entendemos que na construção contínua desse processo os profissionais precisam ter leituras referentes a temas, como: reforma psiquiátrica, família, psicologia, filosofia, dentre outros. Compreendemos que uma assistência de enfermagem que atenda a demanda do indivíduo e de sua família requer um aprendizado que ultrapasse os conceitos teóricos da 
COIMBRA, Valéria Cristina Chistello; GUIMARÃES, Jacileide; SILVA, Mariluci Camargo Ferreira da; KANTORSKI, Luciane; SCATENA, 104 Maria Cecília Morais - Reabilitação psicossocial e família: considerações sobre a reestruturação da assistência psiquiátrica no Brasil. Revista Eletrônica de Enfermagem, v. 07, n. 01, p. 99 - 104, 2005. Disponível em www.fen.ufg.br/revista.htm

reforma psiquiátrica. $\mathrm{O}$ conhecimento teórico juntamente com a sua experiência oferecem subsídios para a discussão, a reflexão, a produção de propostas para a prática de enfermagem na reabilitação psicossocial e a implementação desse cuidado.

\section{REFERÊNCIAS BIBLIOGRÁFICAS}

ARIÉS, P. História Social da Criança e da Família. $2^{\mathrm{a}}$ ed. Rio de Janeiro: Editora LTC, 1978.

BASSIT, W. A família e a doença mental. In: D'INCAO, M. A. (Org.) Doença Mental e Sociedade: uma discussão interdisciplinar. Rio de Janeiro: Graal, 1992.

BERTOLOTE, J. M. Em busca de uma identidade para a reabilitação psicossocial. In: PITTA, A. (org). Reabilitação psicossocial no Brasil. São Paulo: Hucitec., 1996, p.155-158

BIRMAN, J. A Psiquiatria como Discurso da Moralidade. Rio de Janeiro: Graal, 1978.

BRASIL. Ministério da Saúde. Por uma Política de Saúde Mental. Brasília,1999.

CABRAL, B. Estação comunidade. In: JANETE, A.;LANCETTI, A. (org). Saúde mental e saúde da família.

2a ed.São Paulo: Hucitec, 2001. p. 137-154.

COELHO, T. Dicionário Crítico de Política Cultural: cultura e imaginário. $2^{\mathrm{a}}$ ed. São Paulo: Editora lluminura, 1999.

HIRDES, A. Centro comunitário de saúde mental de São Lourenço do Sul ISC: resgatando possibilidades de reabilitação psicossocial. [dissertação] Florianópolis, 2000. Universidade Federal de Santa Catarina.

IANNI, O. A Era da Globalização. $3^{a}$ ed. Rio de Janeiro: Civilização brasileira, 1998.

KANTORSKI, L.P., PITIA, A.C.A., MIRON, V.L. A reforma psiquiátrica nas publicações da Revista "Saúde em Debate" entre 1985-1995. Revista Eletrônica de Enfermagem. v. 4, n. 2, p. 03-09, 2002. [on line] Disponível em http://www.fen.ufg.br/revista/revista4 2/reforma.html. [Acesso em 07 fev. de 2004]
KANTORSKI et al. Serviço de atenção diária de saúde mental - Um espaço de diálogo entre a universidade e os serviços. Rev. da Saúde. URCAMP, v.4. n.1, p.74$82 ., 2000$.

MELMAN, J. Família e doença mental. São Paulo: Escritus, 2001.

NASI, C, STUMM, L.K., HILDEBRANDT, L.M. Convivendo com o doente mental psicótico na ótica do familiar. Revista Eletrônica de Enfermagem. v. 6, n. 1, p. 59-67, 2004. [on line] Disponível em http://www.fen.ufg.br/revista/revista6 1/f6 mental.html. [Acesso em 04 mar. 2004]

PERROT, M. O Nó e o Ninho. In: Veja 25 anos: reflexões para o futuro. São Paulo: Abril S/A, 1993.

PITTA, A. O que é reabilitação psicossocial no Brasil, hoje. In: PITTA, A. (org). Reabilitação psicossocial no Brasil. São Paulo: Hucitec, 1996. p.19-26.

SARACENO, B. Reabilitação psicossocial: uma estratégia para a passagem do milênio. In: PITTA, A. (org). Reabilitação psicossocial no Brasil. São Paulo: Hucitec, 1996 . p.13-18

SARACENO, B. Reabilitação psicossocial: uma prática à espera de teoria. In: PITTA, A. (org). Reabilitação psicossocial no Brasil. São Paulo: Hucitec, 1996a. p.150-154.

SARACENO, B. A concepção de reabilitação psicossocial como referencial para as intervenções terapêuticas em saúde mental. Rev. Ter. Ocup. Univ. São Paulo. v.9, n.1, p.26-31,1998.

SARACENO, B. Libertando identidades: da reabilitação psicossocial à cidade possível. Rio de Janeiro: Editora Te Cora, 1999.

SCATENA, M. C. M. Saindo do hospital psiquiátrico: analise da inserção dos pacientes nos lares abrigados. [livre-docência] Ribeirão Preto: Universidade de São Paulo, Escola de Enfermagem de Ribeirão Preto, 2000.

WERNER, J. Paidéia : a formação do homem grego. São Paulo: Martins Fontes, 1986.

VALENTINI JUNIOR, W. A. H.; VICENTE, C. M. A reabilitação psicossocial em Campinas. In: PITTA, A. (org). Reabilitação psicossocial no Brasil. São Paulo: Hucitec, 1996. p.48-54.

\footnotetext{
*Texto produzido na disciplina de Reabilitação Psicossocial oferecida pelo Programa de pós-graduação em Enfermagem Psiquiátrica do Departamento de Enfermagem Psiquiátrica e Ciências Humanas da Escola de Enfermagem de Ribeirão Preto da Universidade de São Paulo (EERP-USP).

${ }^{1}$ Enfermeira Doutoranda do Programa de pós-graduação em Enfermagem Psiquiátrica do Departamento de Enfermagem Psiquiátrica e Ciências Humanas da Escola de Enfermagem de Ribeirão Preto da Universidade de São Paulo (EERP-USP). Bolsista da CAPES. Endereço:

Avenida do Café, 1139, BI. A Ap. 401 Cep: 14050-230 Bairro: Vila Amélia, Ribeirão Preto - SP. E-mail: valeriacoimbra@hotmail.com

${ }^{2}$ Enfermeira Doutoranda do Programa de pós-graduação em Enfermagem Psiquiátrica do Departamento de Enfermagem Psiquiátrica e

Ciências Humanas da Escola de Enfermagem de Ribeirão Preto da Universidade de São Paulo (EERP-USP).

${ }^{3}$ Enfermeira Doutoranda do Programa de pós-graduação em Enfermagem Psiquiátrica do Departamento de Enfermagem Psiquiátrica e

Ciências Humanas da Escola de Enfermagem de Ribeirão Preto da Universidade de São Paulo (EERP-USP). Docente da Faculdade de

Enfermagem do Centro Universitário de Votuporanga.

${ }^{4}$ Professora Doutora da Faculdade de Enfermagem e Obstetrícia da Universidade Federal de Pelotas. Apoio CNPq

${ }^{5}$ Professora Doutora pelo Departamento de Enfermagem Psiquiátrica e Ciências Humanas da Escola de Enfermagem de Ribeirão Preto da Universidade de São Paulo (EERP-USP).
} 